\title{
Introducing the Guest Editors of this special section of the June 2015 issue of Food Security
}

\section{Richard Strange ${ }^{1}$}

Published online: 16 May 2015

(C) Springer Science+Business Media Dordrecht and International Society for Plant Pathology 2015

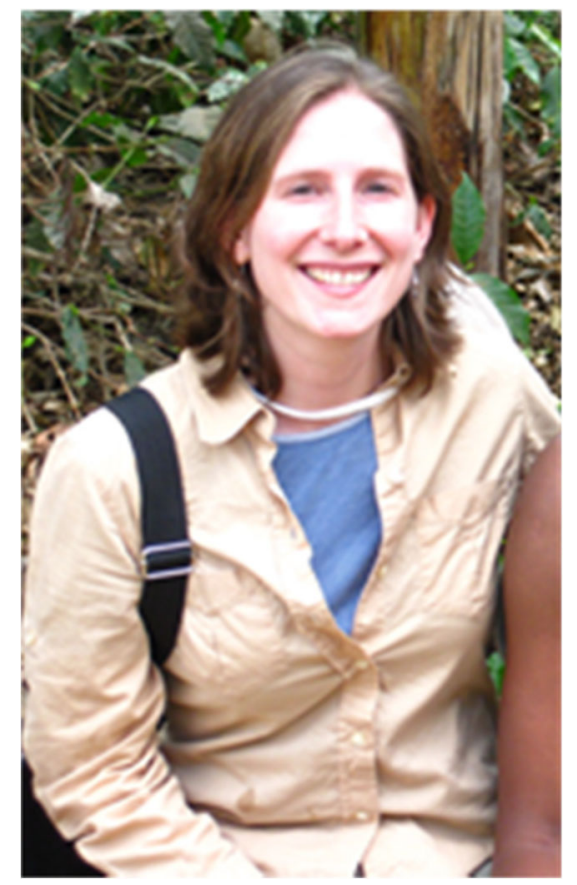

Anna Herforth. Anna Herforth is a consultant specializing in the links between nutrition, agriculture and the environment. She consults for the World Bank, the UN Food and Agriculture Organization (FAO), and USAID's

Richard Strange

r.strange@sbc.bbk.ac.uk

1 Birkbeck College, University of London, London, UK
SPRING Project, among others. She has worked with universities, nonprofit organizations, and the CGIAR on food and nutrition in Africa, South Asia, and Latin America. She holds a Ph.D. from Cornell University in International Nutrition, an M.S. in Food Policy from Tufts Friedman School, and a B.S. in Plant Science from Cornell University. She is a founding member of the Agriculture-Nutrition Community of Practice.

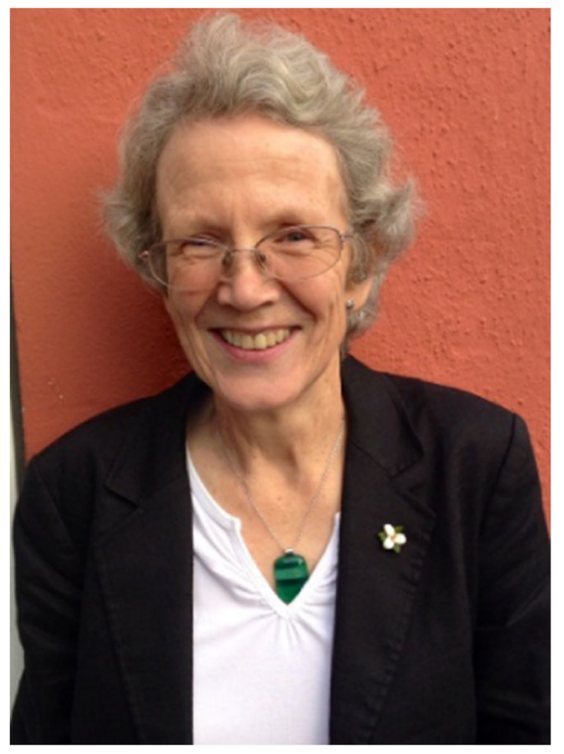

Margaret Gill. Margaret Gill is the Chair of the Independent Science and Partnership Council of the CGIAR and also a Professor of Integrated Land Use at the University of Aberdeen. Previous posts have 
included Chief Scientific Adviser on Rural Affairs and the Environment in the Scottish Government, Chief Executive of the Macaulay Land Use Research Institute in Aberdeen and Chief Executive of Natural
Resources International Ltd. Her research career was originally in ruminant nutrition, subsequently on the impacts of livestock systems on the environment before she moved into research management positions. 